\title{
The human dimensions of global environmental change: Ecosystem services, resilience, and governance
}

A. Rechkemmer and L. von Falkenhayn

\begin{abstract}
Global environmental change affects all societies and their environments at various spatial and temporal scales. The linking of natural ecosystems to social ones is of central importance for the analysis, mitigation of and adaptation to any action or issue related to sustainability and global change. When examining the human dimensions of environmental change, the study of ecosystem services illustrates the strong interlinkages existing between both socio-ecological systems and global change. Ecosystem services are inextricably linked to human well-being and play a central role in sustainable adaptation strategies. Environmental impact of global change can both add to social vulnerability and change resilience by altering the supply of ecosystem services and the trade-offs which can occur. It is when examining such phenomena that the importance and abilities of governance systems to shape change and responses are seen.
\end{abstract}

\section{The added value of "Human Dimensions Science"}

Present global environmental change can, to a large extent, be attributed to anthropogenic activities. Human interferences with the Earth's system are so significant that the recent era has been suitably named the "anthropocene". Human activity continues to intensify sharply and increase pressures on the Earth's recourses and, for instance, on the planets capability to assimilate/absorb wastes (e.g. [8]). Thus, climate change is the most prominent, but only one of the various changes that humanity presently face and which threaten social welfare. Global environmental change also encompasses changes in terrestrial and aquatic ecosystems, and its full extent and complexity is only now being realised. The magnitude and nature of the impacts resulting from global environmental change processes depend upon human responses at all scales (individual, national, international). In this sense, to avoid, for example, dangerous anthropogenic interference in the global climate system, far-reaching behavioural changes will be required.

Natural, life and environmental sciences constantly add to our understanding of the dynamics of environmental change processes. However, traditionally, research on these processes has focused mainly on the biophysical elements which are just one part of these complex and dynamic systems. Research was previously widely based on the assumption that anthropogenic actions are basically of little influence on the workings of these systems or represent only sporadic disturbances that can be discounted for purposes of analysis. In recent decades, there has been an ever increasing realisation that human-environment interactions give rise to complex and dynamic socio-ecological systems in which both anthropogenic and biophysical drivers play central roles. The current challenge is to understand the dynamics of these coupled socioecological or human-biophysical systems well enough to anticipate large-scale changes and to take steps either to reduce their likelihood or to minimize their impact once they do occur. Therefore, in order to better understand and to respond effectively to global environmental 
changes, in addition to the natural sciences, major inputs from the social sciences are required to provide crucial insights into the social dynamics of global environmental change. It is only when the social element is linked with the environmental element that ecosystem change and successful implementation of coping strategies and resource management can be achieved. A science of coupled systems is required, where anthropogenic impacts are integrated into analyses of global environmental changes. The "socio-component" thereby can be broadly defined as the 'human dimensions' of global change.

Human societies define the boundaries and character of their environments, frame their environmental problems, and devise "solutions" to them, based on their perceptions of what constitutes the environment, what drives and constrains its dynamics, what creates environmental challenges, and what may be done to deal with them. The "Human Dimensions Science's" approach is to place society at the centre of the global environmental change debate, a perspective that frames current global problems as social and societal challenges.

Research on the human dimensions of global environmental change poses a number of methodological challenges. Many associated concepts like ecosystem services, sustainable development or human security are difficult to measure, especially in a manner that permits comparisons across space and time. Another barrier is the interaction of numerous variables with one another to form causal clusters whose constituent elements are hard to separate. These new challenges have also contributed to the pronounced tendency in this recently established study field to engage in methodological innovation and trans-disciplinary cross-fertilization.

In Figure 1, the three-dimensional framework of research on the human dimensions of global environmental change is displayed, consisting of the predominant research areas, crosscutting themes and the main methodologies employed. The main research areas include Human Security, Land Use and Land Cover Change, Industrial Transformation, Governance and Food Systems. A key feature of the framework is the cross-cutting themes that are of essential importance and relevance for each of the research areas. Finally, the mentioned methodologies are often innovative as they must address trans-disciplinary challenges. For example, enhanced statistical methods or the ever growing field of simulation and modelling is one of the crucial factors that have helped lift global change science into a new realm of importance.

Taking as an example the case of Land Use and Land Cover Change (LUCC) for a study of the human dimensions of global environmental change, the complexity and the interdependence of numerous factors (e.g. cross-cutting themes) become clear. Anthropogenic land use and drivers of land cover change are a prime source of Global Environmental Change (GEC) and is central to several of the most complex and urgent problems humankind is globally facing. These problems have both a social as well as an environmental dimension. For example, issues as broad in scope as human health, ensuring adequate food production, reducing poverty and climate change are linked to changes in land use and cover. Consequently, it is not possible to find solutions to these problems without understanding and addressing the social elements linked to change such as how governance and policies affect land use and impact on ecosystem functions and vulnerability.

Land use (e.g. agriculture) and land cover (e.g. deforestation) change is, after the use of fossil fuel, the second largest source of greenhouse gases and therefore a prominent driving force of climate change [24]. However, land use changes are triggered by social phenomena such as poverty or global markets. For instance, deforestation occurs due to increased pressures for timber resources and arable land and is a prime example of problems that result from poor land management and population growth. The numerous flow-on negative affects of deforestation include the loss of ecosystem services and goods they provide (i.e. biodiversity, pollination, carbon sequestration).

Research on LUCC consequently aims at answering questions on: 1) the dynamics of land systems (e.g. effects of globalisation on regional decisions and practices, biophysical effects on ecosystem structure and functioning), 2) the consequences of land system changes (e.g. consequences of ecosystem structure change on the delivery of ecosystem services). These research aims reflect both the social and environmental dimensions of the problem and related research can consequently only be fully answered in a joint effort by social and natural scientists. 


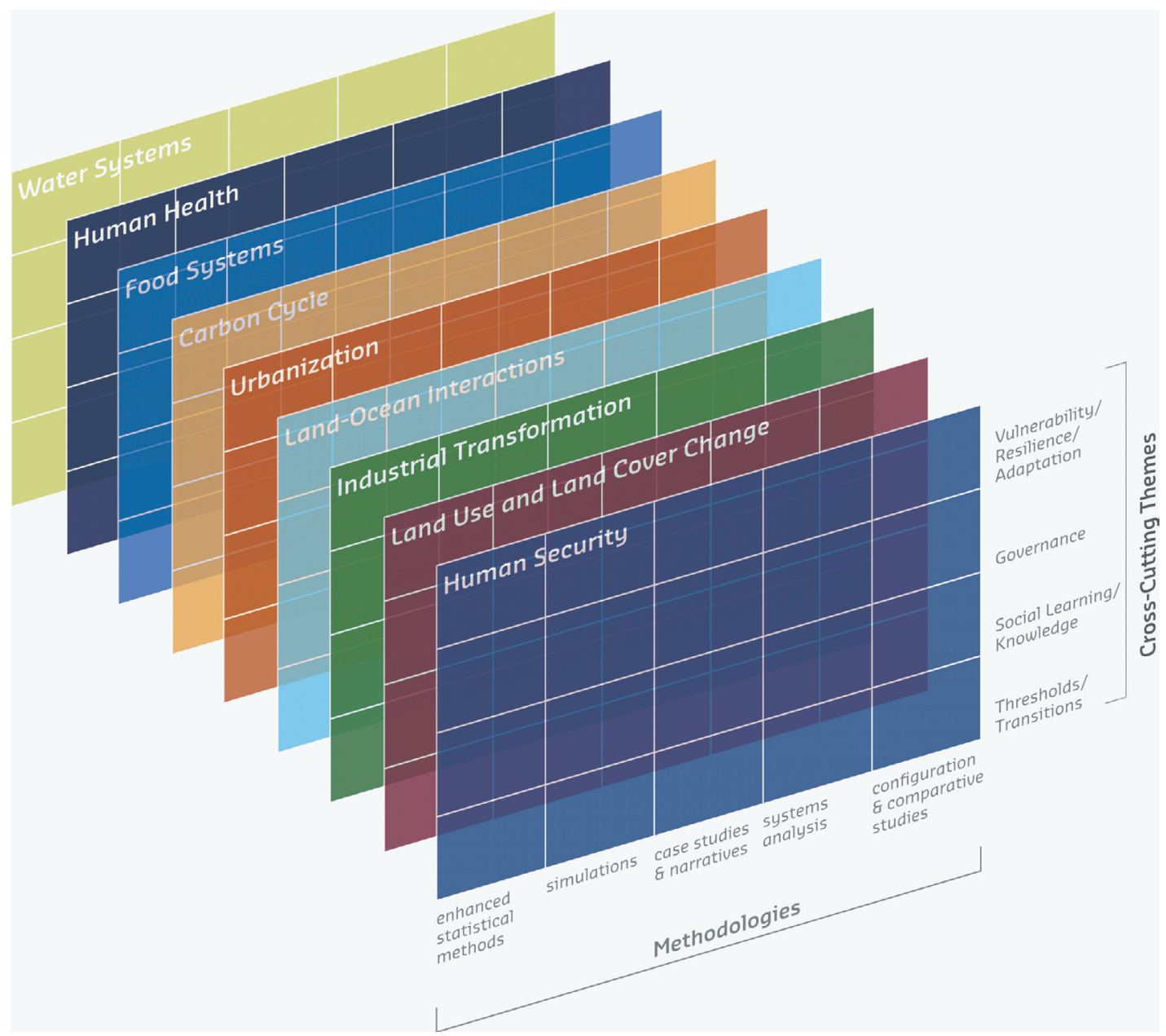

Fig. 1. Framework of research on the Human Dimensions of Global Environmental Change.

The methodologies that are being employed to analyse such problems are often innovative due to the approach of studying complex coupled socio-ecological systems. The use of enhanced statistical methods including methods that enable separation of the relative importance of multiple driving forces is just one example. New forms of meta-analysis are used to analyse the determinants behind land use systems and land cover change processes. A key feature is also the use of models and simulations to explore conditions that can lead to thresholds and transitions in complex and dynamic systems which are prominent in coupled socio-ecological systems. Ultimately, case and comparative studies are of importance because of the complex array of conditions specific to each region which means that findings are not always universally valid. In order to collect and analyse data researchers make use of advanced methods, such as remote sensing techniques and geographic information systems.

The use of the cross-cutting themes displayed in Figure 1 is of major significance for land use and land cover change research. The study of vulnerability/resilience/adaptation and thresholds/transitions of a system can give important insights into why and how a system will be impacted and respond to events and pressures and what can be done to reduce the magnitude of response. Governance is another deciding field that requires ongoing and innovative research as long-term policy making and prevailing governance patterns can directly influence land usage and land cover change and are two of the major determinants of land degradation. The last theme to be addressed is social learning/knowledge, a field that is crucial and key to addressing global change as it addresses behavioural change. The study of the dynamics and pathways of behavioural change is currently one of the greatest challenges for social science. 
When examining global environmental change using the aforementioned research matrix, the related processes, including land use/cover change or climate change more generally, affect all ecosystems (both structure and functions) either directly or indirectly and will thus impact both the vast array of ecosystem services and the people which rely on them. Ecosystem services play a central role in adaptation, resilience to and mitigation of such change. Over the past decade there has been growing recognition that not only the services themselves but also the capacities of ecosystems, which are shaped by human actions and governance systems, to supply these services, provide the foundation for social and economic development [16]. In this context it is important to consider that even in our technologically advanced age humanity fully depends on ecosystems and their services. It is therefore evident that when discussing the human dimensions of global environmental change it is crucial to explore the element of ecosystem services.

\section{What are ecosystem services?}

An ecosystem consists of plants, animals (including humans) and micro organisms that live in biological communities and which interact with each other and with the physical and chemical environment, with adjacent ecosystems and with the water cycle and the atmosphere [34]. These interactions, for instance among species in a food web and their relation to biogeochemical cycling, are complex, non-linear, and contain lags and discontinuities, thresholds and limits. Consequently, ecosystems are considered complex, self-organising systems, across both temporal and spatial scales [24]. Additionally, as these systems are evolutionary (rather than mechanistic) they exhibit a limited degree of predictability [9]. These complexities are reflected in the nature of ecosystems services, their availability, quality and quantity, and this differs from ecosystem to the next.

Ecological systems and their services play a fundamental role in supporting life on Earth at all hierarchical scales. For instance, they are essential in global material cycles like the carbon and water cycles. Partly as an outcome of the global concern for service loss and over the disappearance of natural ecosystems and habitats the Millennium Ecosystem Assessment, was initiated by the United Nations in 2001. This assessment aimed to understand society's dependence on ecosystems and their services. The Millennium Ecosystem Assessment [31] defines 'ecosystem services' as, 'the benefits people obtain from ecosystems' and classes services into the following four categories;

Provisioning services provide goods such as food, freshwater, timber, and fibre for direct human use.

Regulating services maintain a world in which it is biophysically possible for people to live and provide benefits such as pollination of crops, water damage mitigation, and climate stabilisation.

Cultural services make the world a place in which people want to live; they include recreation as well as aesthetic, intellectual, and spiritual inspiration.

Supporting services are the underlying ecosystem processes that produce the direct services described above, including the preservation of options; they include such services as nutrient cycles and oxygen production.

Illustrated in Figure 2 is a characteristic river catchment and some of the many ecosystem services associated with such a catchment. Typical provisionary services supplied by a catchment will for example include timber or fresh water, while regulating services will encompass pollination. A cultural service associated with a river catchment may be that of recreation and a supporting service will include soil development and wildlife habitat.

\section{Linkages between ecosystem services and human well-being}

Ecosystem services whether the provisioning or cultural kind matter and contribute to the well-being of humans. Food, fertile soils, clean water and recreation are just a few of the many services provided by nature to humans. The provision of these services, the reliability of supply, 


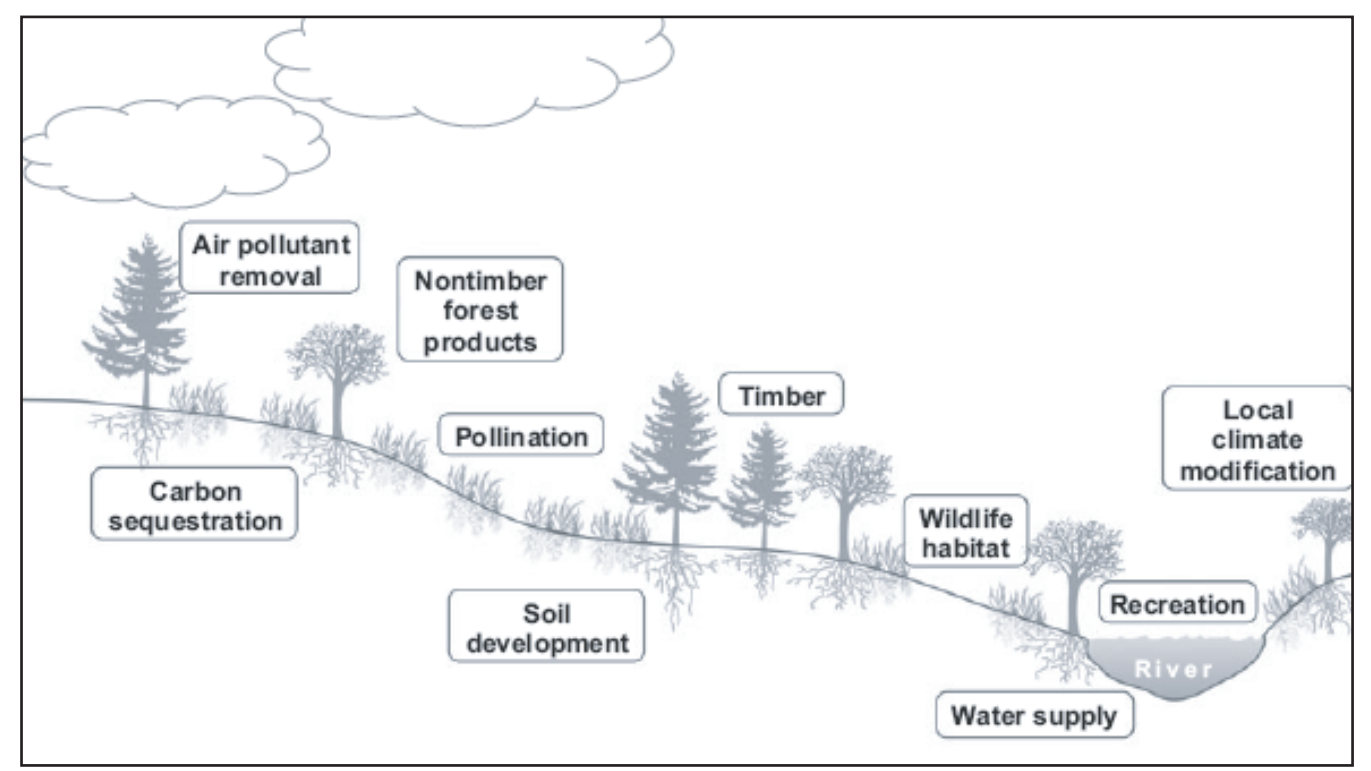

Fig. 2. Ecosystem services of a river catchment (Source: [5]).

their quantity and quality, influence human security, basic material for a good life, health, good social relation and ultimately our freedom and choices, in short our well-being (Millennium Ecosystem Assessment [31]). Figure 3 outlines both the four categories of ecosystem services and the constituents of human well-being. It additionally pictorially illustrates the strengths of linkages between categories of ecosystem services and components of human well-being that are commonly encountered. What is not represented in this figure is that the relationship between services and well-being can be both bidirectional and reinforcing, for instance, the relationship between nutrient depleted soil and people with illnesses. Populations experience ill health and poverty because of under-nutrition and material lack from soil exhaustion and are thus also likely to be deficient in the human capability needed to improve local soil quality [58]. Although people are often buffered from the natural environment by culture and technology, ultimately our livelihoods, health and even survival are completely dependant on ecosystem services and our access to them. Social systems and natural systems are inseparable [44] and there is an increased use of terms such as socio-ecological systems. However, human action is changing many aspects of the earth's environments, its climate, land cover, oceans and the biochemistry of the fundamental cycles that sustain life and the diversity of life itself $[46,59]$. Environmental impacts of global change can add to human and ecosystem vulnerability by altering the supply of ecosystem services $[7,45]$. Global change such as the impacts of climate change on ecosystems and their services will not be distributed equally around the world [13]. This is likely to cause additional inequalities if change disproportionately affects the poor [50] who are most vulnerable because they directly depend on local natural resources. Indigenous people and those with subsistence livelihoods with limited access to information and few means to adaptation will be especially vulnerable to any changes of ecosystem services.

\section{Ecosystem change, vulnerability, and resilience}

Climate change has been occurring naturally for millions of years and the Earth's biosphere has been exposed to large variability and extremes of $\mathrm{CO}_{2}$ and climate. However, anthropogenic climate change has occurred over a much smaller time scale and has had a greater magnitude of change. Ecosystems are sensitive to climate change. For instance, significant biological changes, such as species extinctions, have accompanied large climatic perturbations of the past 


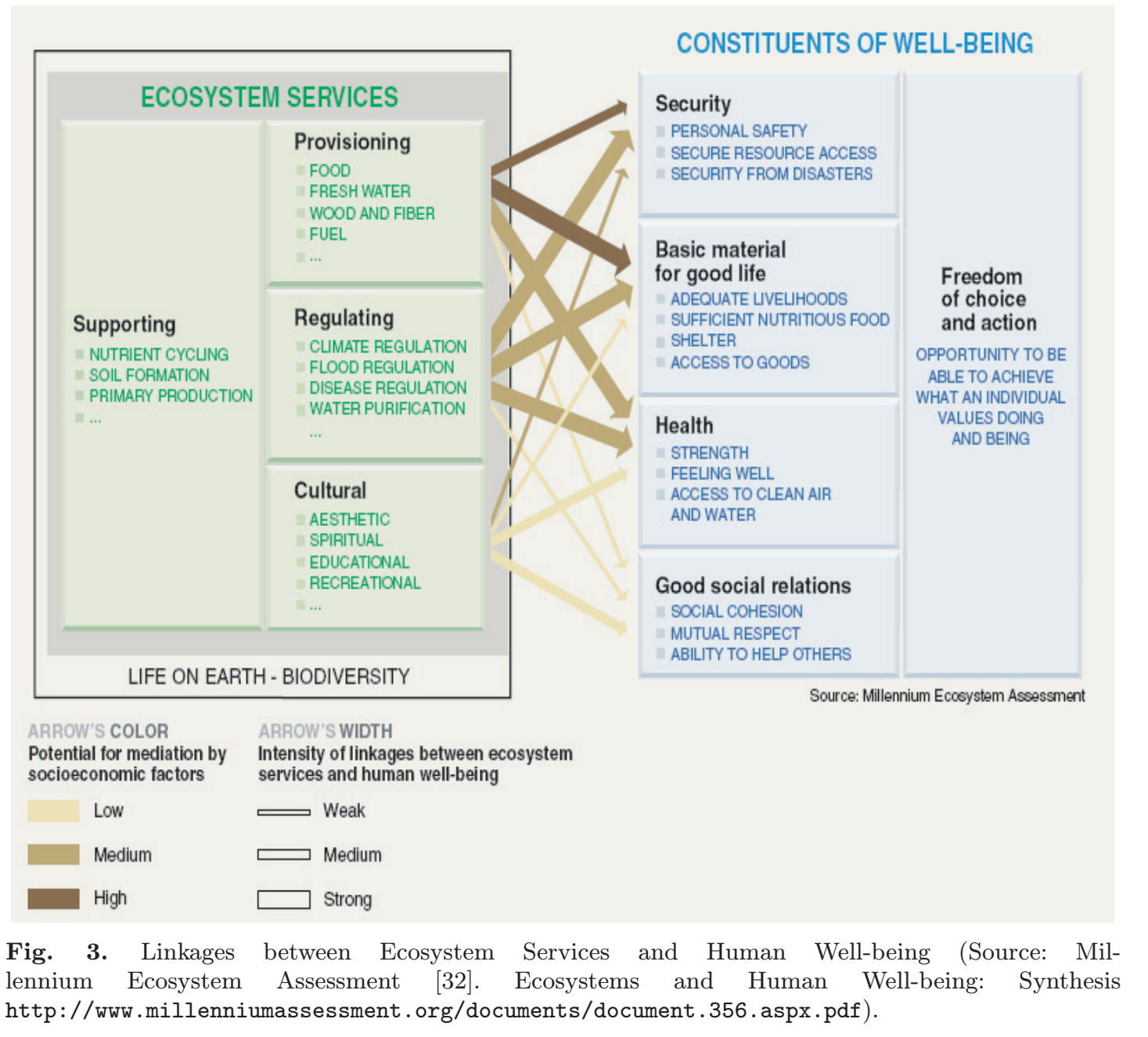

(e.g. [36]). More recently, disruptions in precipitation regimes in the Pacific region, such as those in Australia during El Niño/Southern Oscillation (ENSO) events, can disrupt vegetation cover and composition through drought, heat stress, spread of parasites and disease (e.g. [10]). However, ecosystems are not only sensitive to climate change but also to anthropogenic changes such as land use, pollution and invasive species. While climate change has been estimated to be a major driver of biodiversity loss in tropical and cool conifer forests, and coral reefs [30,51], in other ecosystems land-use changes may be a stronger driver of biodiversity loss, especially in the short term [13]. Land-use change and related habitat loss and fragmentation have long been recognised as important drivers of past and present ecosystem change, particularly biodiversity loss [22]. Additional, prevalent examples of drivers of ecosystem change are changes in fire regimes and exotic species. Fire influences community structure by favouring species which are fire tolerant and consequently change the biodiversity of a region. Introduction by humans of invasive exotic species represent a major threat to endemic or native biodiversity in both terrestrial and aquatic systems [47]. Overall, ongoing shifts in anthropogenic disturbances such as fire regimes are important in altering ecosystem structure, diversity and function (e.g. [53]). These environmental changes will of course then also affect the provision of an ecosystem service. Consequently, it is important to be aware of the synergistic effects of these multiple drivers, both natural and anthropogenic, climatic and non-climatic. This is difficult, however, due to non-linear rapid, threshold type responses in ecological systems [4] and, despite the importance of multiple drivers of ecosystem change, they are rarely included in climate and ecosystem models used for assessing climate change impacts on ecosystems and their services $[12,19,57]$. 


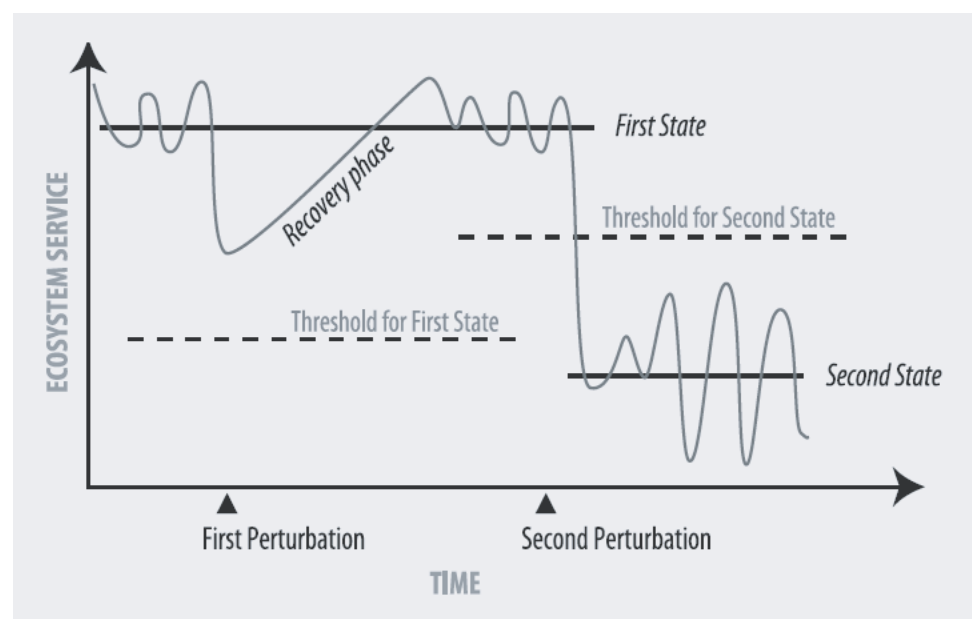

Fig. 4. Dynamics and Stability in Ecosystem Services (Source: Millennium Ecosystem Assessment 2005. Ecosystems and Human Well-being: A Framework for Assessment http://www.millenniumassessment.org/documents/document.300.aspx.pdf).

There are multiple drivers of ecosystem change which impact on the production, quantity and quality of services. An ecosystem response to impacts depends not only on the increasing magnitude of the driver of change but also on the threshold of a system. Many ecosystems do not respond to changes in a linear fashion but rather thresholds are reached and surpassed and rapid, non-linear changes follow. Ecosystems may have more than one state with a self-stabilising mechanism, so that a shift between states does not occur frequently and is not readily reversible [17]. If thresholds in magnitude or rate of change are surpassed then transitions between ecosystem states may be triggered to a less desired state [15], or the ecosystem may even collapse to a much less productive and/or species poor assemblage with lower biomass and other impairments. Passing a threshold marks a sudden change in feedbacks in the ecosystem can bring about sudden, sharp and dramatic change in the responding state variables, for example, the shift from clear to turbid water in lake systems [6]. These large changes are termed regime shifts (illustrated in Figure 4). Regime shifts are increasingly reported in natural environments [43] and are large system changes that are beyond the normal range seen at the microscopic scale (e.g. stable points and limit cycles) [17]. Regime shifts are difficult to predict in part because there is a dearth of knowledge about capacities and vulnerabilities. The theoretical basis for regime shifts has been described by such researchers [i.e. 3,6,43]. Figure 4 illustrates the level of provisioning of an ecosystem service that has been perturbed twice. The dashed lines represent the two thresholds. The natural variation of an ecosystem service is represented during its initial state, before and after the first perturbation. It is evident that the ecosystem service is resilient to the first perturbation and recovers to a stable state. However, the service has become vulnerable to change and this is indicated by the lower threshold for the second state. The second perturbation causes the service to cross the second threshold, which leads to a regime shift and an alternative stable state.

Undesired shifts between ecosystem states are caused by a combination of the magnitudes of external forces and the internal resilience of the system. As resilience declines the ecosystem becomes more vulnerable, and progressively smaller external events can cause shifts. Resilience is the capacity of a system to absorb disturbance and reorganise while undergoing change so as to retain essentially the same function, structure, identity and feedback [54]. Alterations to ecosystems in many cases change the natural self-stabilizing mechanisms inherent in ecosystems such as those that resist daily and seasonal changes in temperature and light conditions [17] increasing ecosystems vulnerability. Consequently, regime shifts in ecosystems are increasingly common as a result of external forces such as human activities that erode resilience for example through the exploitation, pollution and land use change, climate change impact and altered 
disturbance regimes. These impacts, which have increased in intensity since the industrial revolution, have reduced the capacity of ecosystems to cope with change. Triggers for regime shifts are often slow variables such as global warming and nutrient loading [3] which originate from anthropogenic impacts as emissions of $\mathrm{CO}_{2}$ and polluted water from industrial and agricultural activities. When these impacts exceed the internal resilience and threshold of a system a regime shift may manifest itself in ecological surprises such as rapid and abrupt changes in temperature and precipitation, leading to an increase in extreme events such as floods and fires and the irreversible loss of ecosystem services which were dependant on the previous state [41]. Although studies on regime shifts have just begun and there are many unknown issues to be challenged, such as the prediction of threshold points, there are many examples of regime shifts in ecosystems and their consequences for humans.

A continental scale example of an irreversible shift occurred in Australia where the over hunting and use of fire by Aborigines approximately 30,000 to 40,000 year ago removed large marsupial herbivores. Without these animals to prevent fire and fragment vegetation, an ecosystem of fire and fire-dominant plants expanded and irreversibly changed the ecosystem from a state dependant on rapid nutrient cycling to a less productive state with slower cycling [14]. This has consequently impacted on the agricultural productivity of the land and the magnitude and quality of ecosystem services available to the present society. Society then becomes less resilient to change as it has less resources and variety of resources from which to draw from. As humans continue to impact on the global environmental, regime shifts in ecosystems are not just ecological problems causing changes in ecosystems services, but they also become economic problems leading to changes in human well-being.

\section{Recognising trade-offs}

Over time humans have modified their environments and the supply of ecosystem services to enhance, delivery or production of a particular service. However, ecosystem services are not independent of each other [20,37] and the relationships between them may be highly nonlinear [11]. Consequently, attempts to optimise a single ecosystem service often lead to reduction or losses of other ecosystem services - in other words they are 'traded-off' [23,42]. A trade-off between services may be an explicit choice or it may arise without premeditation or even awareness that it is taking place. For example, forested areas provide a variety of extractive and non extractive goods and services. If a region is managed for mining this may decrease its value for carbon sequestration, flood control or biodiversity reserves. In Mali, where natural wetland habitats have been transformed into agricultural land, the increased rice production decreased child stunting and increased well-being, but it has negatively impacted water quality and caused higher occurrences of floods [56]. Such ecosystem service trade-offs arise from management choices made by humans which can change the type, magnitude and relative mix of services provided by an ecosystem [42]. Unintentional trade-offs happen when humans are ignorant of the interactions among ecosystem services [52], their function, or when they have no explicit value/markets. Current decisions show a preference for provisioning services [42] such as food supply and freshwater, which are basic requirements for human well-being. This preference is projected to occur, in part, at the expense of other regulating and supporting services including genetic resources, habitat provision and climate regulation.

The effects of trade-offs can be felt at all spatial scales, locally or at a distant location. Spatial trade-offs are most likely to occur when ecosystem service management decisions are borne by people other than those benefiting from the targeted service. For example in Australia, shortage of rainfall in the upper catchment of the Murray River coupled with water diversion for irrigation and damming has affected downstream environments hundreds of kilometres away. Water shortage downstream in Southern Australia has adversely impacted recreational fishing, tourism, agriculture, preservation of the Coorong National Park and salt dilution processes. Trade-offs across time occur when decisions focus on the provision of an ecosystem service at the expense of this same service or other services in the future [42]. For instance, a current 
major problem in Australia is the large scale salinization of land, lakes and rivers. About 5.7 million hectares are currently at risk or affected by dryland salinity and this is predicted to rise dramatically [33]. Extensive land clearing during the past 200 years has removed deep rooted native vegetation to make way for shorter rooted agricultural crops and pasture grasses that transpire less water. Australia's short term focus on clearing of the land for agriculture led to long term loss in soil quality due to salinity from rises in the water table. This decreases economic output and thus increases the vulnerability of farming communities and their environment to further change.

\section{The missing links}

How do ecosystem services interact and work together? What are the thresholds and resilience of an ecosystem and its services? How can governance facilitate sustainable management of ecosystem services, manage the effects of trade-offs between services, and consequently decrease their vulnerability? Each of these questions illustrates just a few of the current knowledge gaps when tackling the global problem of addressing and adapting to changes in ecosystems services. Effective response depends on knowledge of regional climate and ecological changes and their interactions with society.

Current ecosystem models can translate climate and land changes into changes in ecosystem service supply [44]. However, ecosystem models need a transdisciplinary collaborative approach, for instance prediction models are needed which take into account climate change, ecosystems at all levels and human impact such as poverty. This is not possible while we have an incomplete understanding of the socio-ecological system. Coupled with this, monitoring environmental change including climate and associate ecosystem responses is vital to allow for adjustments in management strategies.

Consequently, one of the first aims should be to raise social, political and scientific awareness of the importance of ecosystems and the services they provide and the complexity which exists between them. The Millennium Assessment has done this to a good extent. But many more studies are needed to identify services, how services interact and to quantify such things as the supply of services and thresholds. Additionally, the awareness of the importance of ecosystems and services should be promoted at all societal levels as human well-being is inextricably linked to ecosystem services. Scientific and political awareness alone is not enough, local awareness is just as important especially in developing countries where the local communities often alone manage the impact on ecosystems and especially their provisional services. For societies to adapt and respond to change, "the public" needs to become more informed and engaged, and scientists and policy makers must also take on the responsibility to learn from, understand, and respond to their community's knowledge, concerns, and needs, if research and policy are to lead towards sustainability. Consequently, it is important that both an increase in knowledge and awareness is coupled with a multidimensional and transdisciplinary approach to address issues of global environmental change.

Global environmental change is a global issue and affects all scales, local, regional, national and global. Thus efforts to maintain and enhance resilience and adaptation to the long-term effects of change need to be addressed by all levels of governance. In situations in which uncertainties and change are key features of the ecological systems and social organisation, critical factors for sustainability are resilience, the capacity to cope and adapt, and the conservation of sources of innovation and renewal [27]. Interventions in social-ecological systems with the aim of altering resilience, whether it is an ecosystem service or a community, immediately confront issues of governance. Who decides what should be made resilient to what? For whom is resilience to be managed, and for what purpose? How do certain attributes of governance function in society to enhance the capacity to manage resilience?

The increased unpredictability and scale of current environmental changes are becoming more difficult to deal with, and new adaptations are required. Adaptation to environmental change, including climate change, involves a diverse range of environmental services, which enable people to sustain their livelihoods, to diversify their production strategies and to incorporate adaptive management schemes into their domestic infrastructures. Ecosystem managers, 
whether political, local or indigenous, can proactively alter the context in which ecosystems develop [13] thus improving resilience. This involves not only anticipatory adaptation options and responses but also resilience which is largely involved in the process of adaptation. Societies need to strengthen their capability for responding and adjusting to disturbance and uncertainty, while keeping their livelihoods flexible and open to change. Enhancing resilience involves many elements including, innovation, knowledge and learning, diversity, adequate human-environment interactions and the capacity of self-organisation, all of which can be governed.

\section{Governing the world's ecosystems: The issues of scales and globality}

A lot has been said and written on globalization, global governance, and more specifically, on global environmental governance within the past decade. Significantly enough, the terms ' $g l o b$ alization' and 'global governance' are relatively new. Statistics show that their use in literature, science and rhetoric has basically started to become fashionable only in the early nineties $[1,2]$. Markets promote efficiency through competition and the division of labour - the specialization that allows people and economies to focus on what they do best. Global markets offer greater opportunity for people to tap into more and larger markets around the world. It means that they can have access to more capital flows, technology, cheaper imports, and larger export markets. But markets do not necessarily ensure that the benefits of increased efficiency are shared by all. Thus the issue of globalization cannot be simplified as 'free trade' agreements, or the policies of the World Bank. It needs to be understood more systemically as a global process. A thorough reorganization of the world's economic and political activity is underway, with takeover tendencies of governance patterns by transnational corporations and the established international trade bureaucracies.

It is evident that there are close links between the phenomenon of globalization and others commonly referred to as global environmental problems: Through the environmental implications of economic activities there is also an environmental globalization taking place.

In conformity with a comprehensive classification established by the German Advisory Council on Global Environmental Change (WBGU), Udo E. Simonis names global environmental problems "changes in the atmosphere, in the oceans, and on land the causes of which can be attributed, directly or indirectly, to human activities; these changes affect the natural metabolic cycles, the aquatic and terrestrial ecological systems, as well as economy and society" [48] : 3 . Environmental problems can be categorized along three levels of appearance. 'Local phenomena' are limited to the spatial dimension of states, e.g. emissions in industrial zones, air pollution caused by traffic in urban areas, or the locally limited contamination of a river through chemical waste. 'Regional phenomena' are of a transboundary, but regionally limited nature, e.g. pollution of transborder river basins, or drought periods. 'Global phenomena' affect worldwide shared resources and sinks, e.g. climate change and global warming, the pollution of the oceans, or loss of genetic diversity. Definitional considerations suggest that only global phenomena are of international concern. However, emphasis has to be laid on the fact that also local or regional problems may culminate to the extent of a global dimension. To give just one example: a regional drought catastrophe may trigger chain reactions such as agriculture production loss, famine and poverty, migration or social unrest [38].

Not all globally known environmental problems are due to or interrelated with globalization effects [39]. However, we discriminate two types of interaction: firstly, we know of grave environmental problems that are caused or increased by globalization-related phenomena, e.g. land degradation caused by unsustainable land use, and production patterns due to world market forces, the climate and energy dilemma $-\mathrm{CO}_{2}$ emissions, the greenhouse effect - due to world wide industrialization processes and 'exported' unsound technologies, or unsustainable energy consumption triggered by enhanced global mobility. Secondly, there are intermediate consequences such as the erosion of environmental safety standards due to competition pressure reference can be made, for example, to the deforestation of rain forests, or textile production patterns in Asian countries [1,2]. The interrelatedness of such issues, as mentioned above, is 
as obvious as are the mutual linkages between the said levels of occurrence: the local, regional, and global ones. ${ }^{1}$

There is broad consensus in the natural as well as social sciences as far as the identification of a number of environmental problems usually referred to as global is concerned: the cluster of climate change phenomena including ozone layer depletion and global warming, loss of genetic (or biological) diversity, deforestation, soil erosion, land degradation and desertification, the contamination and other critical impacts on the world's oceans and other international waters, scarcity of international freshwater resources, problems with waste and chemicals, and the use of non-renewable energies [26].

\section{Global environmental governance in a changing world}

What defines global environmental governance? Enlightening for the understanding of the concept in question, Maria Ivanova contributed the following elaboration to the discourse:

"Two traditional forms of governance have dominated world affairs until recently - national governance through governmental regulation and international governance through collective action facilitated by international organizations and international regimes. However, governing human relations has become a complicated endeavour that has transcended the national and interstate scale and moved to a global level involving multiple actors across national borders and multiple levels of regulatory authority - from subnational to supranational. In this context, institutional arrangements for cooperation are beginning to take shape more systematically and have now been recognized as critical to the effective tackling of any global problem. Public-private partnerships, multi-stakeholder processes, global public policy networks, and issue networks are regarded as important tools for global governance... International organizations are the traditional facilitators of collective action at the international and global level and provide a particularly interesting analytical lens for partnership arrangements. International organizations may perform a range of roles in a partnership context - enabler, facilitator, supporter, or active participant - and influence the shape, form, and function of the collaborative arrangements." ([25]: 9).

Multilateral cooperation thus experiences a redefinition of its genuine connotation. The incorporation of non state actors, scientific community, and non hierarchical patterns render the referred to networks truly multilateral. However, we should not neglect that formal and interstate negotiation processes, under UN aegis, yielding legal agreements or regimes are forming an important part of global environmental governance, just like states as the principal actors among others. Rounding up the definitional framework provided for the term in question, Richard Stewart writes:

"The coming decades pose an enormous challenge of governance for the global community: preserving the planet's ecosystems and protecting the world's common environment while meeting the aspirations of all peoples for higher personal and societal levels of economic welfare. Meeting this challenge will require newly developed and developing countries and public/private international partnerships for sustainable development; wider adoption of economic instruments for environmental and resource protection; improved international mechanisms for risk assessment and resolution of trade/environment controversies; and more focused and effective international environmental laws and institutions..." [49].

\section{Synchronicity of realities}

Without a doubt, it has become quite difficult to create a momentum for a global collaborative effort by all UN member states to solve common problems at this stage, however necessary and desirable that would be. Furthermore, one cannot and should not expect the organs of

\footnotetext{
1 Further recommended articles on the interplay of globalization, environment and global public policies are: Hirst, Paul, 1997: "The Global Economy - Myth and Realities". In: International Affairs: 73: 3; and: Esser, Klaus (1998): "Nationalstaatliches Handeln im Übergang von der Industriezur Informationsökonomie", in: Messner, Dirk (ed.): Die Zukunft des Staates und der Politik. Bonn.
} 
multilateral cooperation, the UN institutions, to provide results that are not brought about by the member states working in concert. Chronic under-financing of the existing instruments simply adds to the difficulties. This could be the time for a practical middle way. Initiatives of individual states or groups of states and their allies of convenience in so called coalitions of the willing may contribute to helping out of the dilemma posed by the current gridlock in the implementation of important environmental measures.

Empirical studies admit the advanced institutionalization of global environmental governance, even as of today. Some 900 agreements have been decided upon. And no one would seriously neglect the growing role of private actors, scientific networks, and Non-Governmental Organizations (NGOs) - seconded by new economic instruments such as certificates trading $[21] .^{2}$ It seems that an adequate description for the present phase in international relations would be synchronicity of realities. While some empirical findings suggest that unilateralism and coalitions of the willing are a paradigm for the contemporary international order, others speak about an age of newly emerging empires. On the other hand, global governance, particularly in the field of environment or sustainable development, is definitely practiced by a multitude of actors worldwide. Analytically speaking, it's all of it in combination. While nation-states will remain the dominant actors for some time, be it as unilateralists, multilateralists, or partners, governance will in any case, in a further globalizing world, comprise new avenues and strategies for joint implementation, so-called type II outcomes or informal agreements, be they between states or in the form of voluntary networks and partnerships [18,40].

\section{Ecosystems, resilience, and governance: Strengthening the human dimensions}

In designing any future international arrangements on environmental issues, it is important to take into account the contemporary political realities at the global level. Many governments' political attention is nowadays directed foremost to societal concerns such as economic, social and human development, poverty reduction, health, water and sanitation, food security, national security and statehood protection. In a number of countries, reduced political status, reduced budgets as well as reduced Official Development Aid (ODA) have hampered progress in the environmental management field. To ensure significant political support for any future objectives, it is thus a prerequisite to explicitly include the crucial issues of enhanced and sustainable management of complex ecosystems and natural resources into the societal agenda of developing countries and actual as well as potential donors.

The majority of background and discussion papers focusing on developed countries tend to propose the following strategic objectives with regards to the global environmental agenda: (a) enhance the conservation of natural resources to ensure long-term benefits for people that depend on them; (b) secure high-level political support to mobilize financial and technical resources; (c) reduce degradation of natural resources and restore degraded areas to a productive state; and, (d) establish partnerships with constituencies external to natural resources to proof contributions of natural resources to the societal agenda of states [29]. Notwithstanding the evident importance of these objectives, such exclusive approaches may not lead to an effectively reshaped and impact-driven new policy for global environmental management. More holistic requirements seem to be needed: the global targets of nature conservation, sustainable resource management, production and trade firstly have to be addressed in a balanced and integrated manner - harmonizing needs and objectives of recipients and donors, producers and consumers alike. Secondly, holism vis-à-vis the environmental agenda means deepening the link between global environmental change and the agenda of human well-being.

Sustainable development is about improving the quality of life for all of the Earth's citizens without increasing the use of natural resources and sinks beyond the capacity of the environment to supply them indefinitely. It underlies an understanding that action has consequences and that humanity must find innovative ways to change institutional structures and influence

${ }^{2}$ On market based means for the public sector, reference is made to the classic: [35]. 
individual behaviour. It is about taking action, changing policy and practice at all levels, from the individual to the general or collective. The Brundtland sustainability definition implies a very important shift from an idea of sustainability, as primarily ecological, to a framework that also emphasizes the economic and social context of development. In this regard, since the $U$ nited $N$ ations $C$ onference on Environment and Development (UNCED), more responsibilities have been placed on states and civil society to protect local, national, sub regional, regional, and global environment, especially those which are the concern of entire communities such as climate change, loss of biodiversity, land degradation, desertification and deforestation. In other words, there was conceptualization of a need for more effective implementation of conventions on environment and development, through integration with domestic law and policy. A number of examples clearly point out the human concerns and need for meaningful incentives for communities and individuals to achieve sustainable development.

It is commonly recognized that global environmental threats such as climate change and global warming are mainly produced in developed countries, and are thus part of the epiphenomena of globalization, but have significant and often disastrous impact on developing countries. Loss of biodiversity, deforestation and desertification are among the most prominent ones, since rainfall patterns change significantly in arid, semiarid and dry sub humid areas. But this is not yet the end of the story. Desertification itself is a driving force for further downstream problems of severe magnitude, such as marginalization of rural areas, economic disaster and poverty, migration, urbanization, and social conflict, just to name some. There is, as has been mentioned above, a clear link between environmental issues, economic development, and more particular, human security. It was of utmost importance already at UNCED to understand what are the linkages, underlying forces, causes and effects or, in other words, to find an answer to the question: how can sustainable development and human security be obtained in the age of globalization? How can the structures, trends and effects of a globalizing world, be utilized to serve the needs of those affected by natural/environmental and socio-economic disaster?

A new paradigm shift for environmental governance is likely to be taking place - in analogy to the one initiated by the Brundtland report leading to UNCED and its outcomes as well as to the conception of sustainable development. Matters related to global environmental change should no longer be treated as a stand-alone, perceiving nature conservation as a good for itself, nor should environmental care be perceived as depending on a certain given state of domestic economic development. The Brundtland nexus between environment and development, which implies mutual interdependence, should not be given up. Moreover, the factor of human wellbeing should be systematically added to the matrix of sustainable development, bringing about a triangular understanding of the inter-relatedness of environmental change, development, and human well-being:

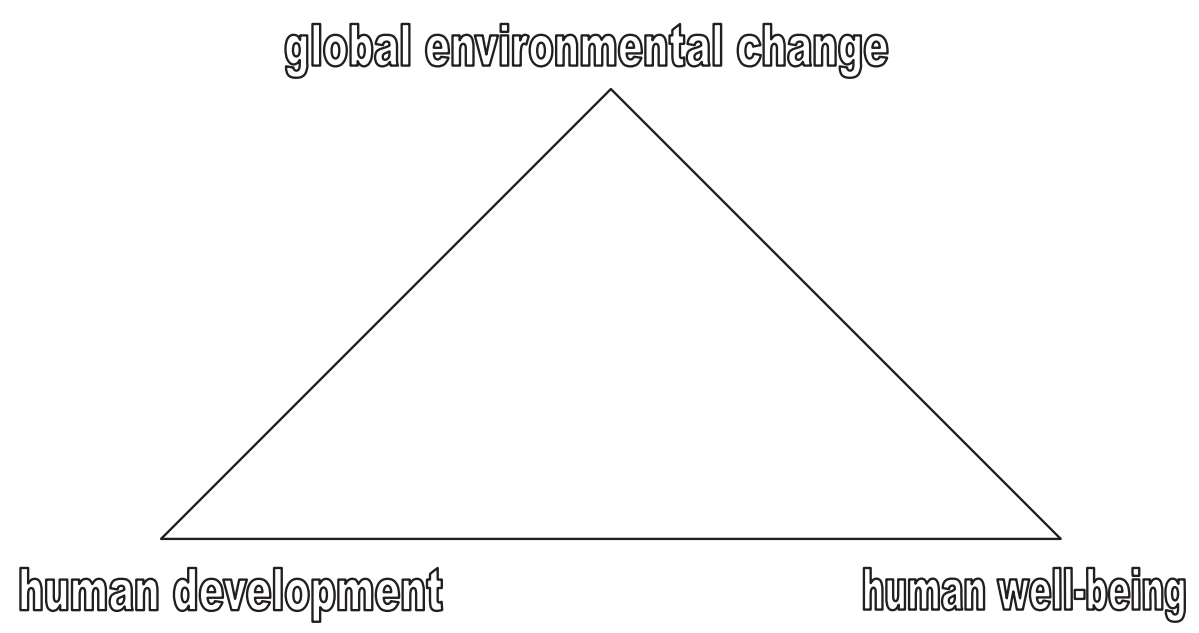


Without any doubt, the human dimensions of global environmental change have meanwhile more than ever before entered the focus of science and policy makers alike. The link between global environmental change and human well-being has nowadays become part of the portfolio of a number of departments and agencies of the United Nations system. In some cases, it constitutes a major, in others, a minor target area. There is evidence that the level of attention towards the working field and issue area in question has gained, yet is of a growing nature.

\section{References}

1. E. Altvater, B. Mahnkopf, Grenzen der Gloablisierung, Münster: Westphälisches Dampfboot (1999)

2. E. Altvater, B. Mahnkopf, Globalisierung der Unsicherheit, Münster: Westphälisches Dampfboot (2002)

3. B.E. Beisner, D.T. Haydon, K. Cuddington, Front. Ecol. Environ. 1, 376 (2003)

4. V.R. Burkett, D.A. Wilcox, R. Stottlemyer, W. Barrow, D. Fagre, J. Baron, J. Price, J.L. Nielsen, C.D. Allen, D.L. Peterson, G. Ruggerone, T. Doyle, Ecol. Complex. 2, 357 (2005)

5. K.A. Brauman, G.C. Daily, T.K. Duarte, H.A. Mooney, Annu. Rev. Env. Res. 32, 67 (2007)

6. S.R. Carpenter, Regime Shifts in Lake Ecosystems: Pattern and Variation, Vol. 15 (Oldendorf/Luhe, Germany, 2003)

7. G.S. Cumming, G. Barnes, S. Perz, M. Schmink, K.E. Sieving, J. Southworth, M. Binford, R.D. Holt, C. Stickler, T. Van Holt, Ecosystems 8, 975 (2005)

8. P.J. Crutzen, Nature 415, 23 (2002)

9. R. Costanza, L. Waigner, C. Folke, K.-G. Mäler, BioScience 43, 545 (1993)

10. H.F. Diaz, V. Markgraf, El Ninio Historical and Paleoclimatic Aspects of the Southern Oscillation (Cambridge University Press, Cambridge, 1992), p. 476

11. S.C. Farber, R. Costanza, M.A. Wilson, Ecolog. Econom. 41, 374 (2002)

12. J.J. Feddema, K.W. Oleson, G.B. Bonan, L.O. Mearns, L.E. Buja, G.A. Meehl, W.M. Washington, Science 310, 1674 (2005)

13. A. Fischlin, G.F. Midgley, J.T. Price, R. Leemans, B. Gopal, C. Turley, M.D. Rounsevell, O.P. Dube, J. Tarazon, A.A. Velichko, Climate Change 200\%: Impacts, Adaptation and Vulnerability. Contribution of Working Group II to the Fourth Assessment Report of the Intergovernmental Panel of Climate Change, edited by M.L. Parry, O.F. Canziani, J.P. Palutikof, P.J. van der Linden, C.E. Hanson (Cambridge University Press, Cambridge, 2007), p. 211

14. T. Flannery, The Future Eaters: An Ecological History of the Australasian Lands and People (Sydney, Reed New Holland, 1994).

15. C. Folke, S.R. Carpenter, B.H. Walker, M. Scheffer, T. Elmqvist, L.H. Gunderson, C.S. Holling, Evol. System. 35, 557 (2004)

16. C. Folke, L. Pritchard Jr., F. Berkes, J. Colding, U. Svedin, Ecol. Soc. 12, 30 (2007)

17. M. Genkai-Kato, Ecol. Res. 22, 214 (2007)

18. B. Hamm, Public-Private Partnerships und der Global Compact der Vereinten Nationen (Duisburg INEF, 2002)

19. A.J. Hansen, R.P. Neilson, V.H. Dale, C.H. Flather, L.R. Iverson, D.J. Currie, S. Shafer, R. Cook, P.J. Bartlein, BioScience 51, 779 (2001)

20. G. Heal, G.C. Daily, P.R. Ehrlich, J. Salzman, C. Boggs, J. Hellman, J. Hughes, C. Kremen, T. Ricketts, Stanford Env. Law J. 20, 364 (2001)

21. C. Helm, U.E. Simonis, F. Biermann, Weltökologie und globale Umweltpolitik, edited by Stiftung Entwicklung und Frieden (ed.), Globale Trends (Frankfurt Main Fischer, 2004/2005)

22. V.H. Heywood, R.T. Watson, Global Biodiversity Assessment (Cambridge University Press, Cambridge, 1995), p. 1140

23. C.S. Holling, G.K. Meffe, Conserv. Biol. 10, 328 (1996)

24. IPCC, 2007, Climate Change 2007: Synthesis Report. Contribution of Working Groups I, II and III to the Fourth Assessment Report of the Intergovernmental Panel on Climate Change [Core Writing Team, R.K Pachauri, A. Reisinger, (eds.)]. IPCC, Geneva, Switzerland, p. 104; S.A. Levin, Ecology 73, 1943 (1992)

25. M.H. Ivanova, Partnerships, International Organizations, and Global Environmental Governance, edited by Witte, J. Martin; Streck, Charlotte; Benner, Thorsten, Progress or Peril? The PostJohannesburg Agenda, Washington DC, Berlin: Global Public Policy Institute (2003)

26. R. Kreibich, U.E. Simonis, Global Change, Berlin Bwv, 2000 
27. L. Lebel, J.M. Anderies, B. Cambell, C. Folke, S. Hatfield-Dodds, T.P. Hughes, J. Wilson, Ecol. Soc. 11, 9 (2006)

28. R.F. Noss, Conservation of biodiversity at the landscape scale, edited by R.C. Szaro, D.W. Johnston, (Oxford University Press, New York, 1996), p. 574

29. J. Maini, Future International Arrangement on Forests (Ottawa, 2004)

30. J.R. Malcolm, C.R. Liu, R.P. Neilson, L. Hansen, L. Hannah, Conserv. Biol. 20, 538 (2006)

31. Millennium Ecosystem Assessment, Ecosystems and their services (Island Press, Washington DC, USA, 2003)

32. Millennium Ecosystem Assessment, Ecosystems and Human Well-being: Policy Responses (Island Press, Washington DC, USA, 2005)

33. National Land and Water Resources Audit (2001), Australian Dryland Salinity Assessment 2000 - extent, impacts, processes, monitoring and management options. A program of the Natural Heritage Trust, published January 2001, Contents accessed via http://audit.ea.gov.au/ANRA/land/docs/national/Salinity_Contents.html

34. E.P. Odum, Sinauer Associates (Sutherland, Massachussets, USA, 1989)

35. D. Osborne, T. Gaebler, Reinventing Government: How the Entrepreneurial Spirit Is Transforming the Public Sector (MA, Reading), 1992

36. J. Overpeck, J. Cole, P. Bartlein, Climate Change and Biodiversity, edited by T.E. Lovejoy, L. Hannah (Yale University Press, New Haven, Connecticut, 2005), p. 91

37. E. Pereira, C. Queiroz, H.M. Pereira, L. Vicente, Ecol. Soc. 10, 14 (2005)

38. A. Rechkemmer, Environmental Refugees and Environmental Migration, in: Gate, 3/200 (2000)

39. A. Rechkemmer, Lösungsansätze für Globale Umweltprobleme, in: Globalisierung. Informationen zur Politischen Bildung 280, Bonn, Bundeszentrale für Politische Bildung, 2003

40. A. Rechkemmer, Sicherheit Frieden 23, 1 (2005)

41. W.V. Reid, et al., Millennium Ecosystem Synthesis Report (Island Press, Washington DC, 2005)

42. J.P. Rodriguez, T.D. Beard Jr., E.M. Bennett, G.S. Cumming, S. Cork, J. Agard, A.P. Dobson, G.D. Peterson, Ecol. Soc. 11, 28 (2006)

43. M. Scheffer, S.R. Carpenter, J.A. Foley, C. Folke, B.H. Walker, Nature 413, 591 (2001)

44. D. Schröter, Vulnerability to Changes in Ecosystem Services (Cambridge, MA: Harvard University, 2005)

45. D. Schröter, M.J. Metzger, W. Cramer, R. Leemans, Environm. Sci. Sect. Bull. 2, 11 (2004)

46. W. Steffen, A. Sanderson, J. Jäger, P.D. Tyson, B. Moore III, P.A. Matson, K. Richardson, F. Oldfield, H.-J. Schellnhuber, B.L. Turner, R.J. Wasson, Global change and the Earth system: A Planet under Pressure (Springer Verlag, Heidelberg Germany, 2004)

47. D. Scavia, J.C. Field, D.F. Boesch, R.W. Buddemeier, V. Burkett, D.R. Cayan, M. Fogarty, M.A. Harwell, R.W. Howarth, C. Mason, D.J. Reed, T.C. Royer, A.H. Sallenger, J.G. Titus, Estuaries 25, 149 (2002)

48. U.E. Simonis, Global Environmental Problems - Searching for Andequate Solutions, WZB Policy Paper (Berlin, 1999)

49. R. Stewart, In Progressive Governance for the XXI Century, Conf. Proc. $20^{\text {th }}$ and $21^{\text {st }}$ November, Florence, 1999

50. N. Stern, The Economics of Climate Change: The Stern Review (Cambridge University Press, Cambridge, 2007), p. 692

51. C.D. Thomas, et al., Nature 427, 145 (2004)

52. D. Tilman, K.G. Cassman, P.A. Matson, R. Naylor, S. Polasky, Nature 418, 671 (2002)

53. K.P. Timoney, Forest Chron. 79, 502 (2003)

54. Walker, C.S. Holling, S.R. Carpenter, A. Kinzig, Ecol. Soc. 9, 5 (2004)

55. Walker, S. Carpenter, J. Anderies, N. Abel, G. Cumming, M. Janssen, L. Lebel, J. Norberg, G.D. Peterson, R. Pritchard, Conserv. Ecol. 6, 14 (2002)

56. C. Wong, M. Roy, A.K. Duraiappah, Published by the International Institute for Sustainable Development for the United Nations environment programme, 2005

57. M. Zebisch, F. Wechsung, H. Kenneweg, Landscape Urban Plan 67, 157 (2004)

58. C.D. Butler, W. Oluoch-Kosura, Ecol. Soc. 11, 30 (2006)

59. Millennium Ecosystem Assessment, Ecosystems and Human Well-being: Current State and Trends: Findings of the Condition and Trends Working Group (Island Press, Washington DC, 2005b) 